\title{
Motivasi belajar siswa KMS di SMPN di Kota Yogyakarta
}

\author{
Zaldhi Yusuf Akbar \\ Program Studi Psikologi, Fakultas Psikologi, Universitas Muhammadiyah Purwokerto \\ zaldhi@ump.ac.id \\ Farhan Zakariyya \\ Program Studi Psikologi, Fakultas Ilmu Pendidikan, Universitas Pendidikan Indonesia \\ farhanzakariyya@Upi.edu
}

\begin{abstract}
ABSTRAK
SMP N A Yogyakarta menerima siswa-siswa kurang mampu atau siswa KMS berjumlah 60 orang setiap tahunnya. Terdapat permasalahan pada siswa-siswa KMS, salah satunya siswa KMS memiliki motivasi yang kurang, prestasi akademik yang rendah, dan beberapa siswa KMS memiliki sikap yang kurang baik di dalam kelas. Tujuan penelitian ini adalah untuk mengetahui motivasi belajar dari siswa KMS di SMP N A di Kota Yogyakarta. Penelitian yang dilakukan akan mengungkap motivasi belajar siswa KMS pada taraf rendah, sedang atau tinggi. Penelitian ini menggunakan kuantitatif survey menggunakan alat ukur skala motivasi belajar dan ditambahkan data wawancara dan observasi terkait motivasi belajar siswa KMS di sekolah. Subjek penelitian adalah siswa kelas 7 yang berjumlah 57 siswa SMPN A di Yogyakarta. Penelitian berdasarkan skala motivasi belajar di dapatkan bahwa siswa KMS memiliki motivasi belajar kategori rendah sejumlah 15 siswa, kategori sedang 39 siswa dan kategori tinggi 3 siswa.
\end{abstract}

Kata Kunci: Motivasi Belajar, Siswa KMS, SMP N A

\begin{abstract}
SMP N A Yogyakarta accepts underprivileged students or $60 \mathrm{KMS}$ students every year. There are problems with KMS students, one of them KMS students have less motivation, low academic achievement, and some KMS students have less good attitude in class. The purpose of this study was to determine learning motivation of KMS students at SMP NA in Yogyakarta City. The research conducted will reveal the learning motivation of KMS students at low, medium or high level. This study uses a quantitative survey using a scale of learning motivation scale and added interview and observation data related to KMS students' learning motivation at school. The research subjects were 7 th grade students, totaling 57 students of SMPN A in Yogyakarta. Research based on the scale of learning motivation found that KMS students had low learning motivation categories of 15 students, medium categories of 39 students and high categories of 3 students.
\end{abstract}

Keywords: Learning Motivation, KMS Students, SMP N A

\section{PENDAHULUAN}

Perubahan dan perkembangan yang terjadi pada masyarakat dunia saat ini menimbulkan persaingan yang semakin ketat antar bangsa dan dalam berbagai bidang kehidupan. Untuk menghadapi persaingan tersebut maka diperlukan sumber daya manusia yang berkualitas tinggi. Pembangunan sumber daya yang 
Jurnal Psikologi Terapan dan Pendidikan

ISSN: $2715-2456$

Vol. 1, No. 2, November 2019, pp. 136-142

berkualitas tinggi pada dasarnya adalah untuk menciptakan dan mengembangkan ilmu dan teknologi yang modern sebagai sarana mewujudkan suatu masyarakat yang maju, mandiri, dan sejahtera.

Salah satu cara agar sumber daya manusia dapat berkembang dilakukan menggunakan jalur pendidikan. UU No. 20 Tahun 2003 membahas tentang sistem pendidikan nasional "Pendidikan nasional berfungsi mengembangkan kemampuan dan membentuk watak serta peradaban bangsa yang bermanfaat dalam rangka mencerdaskan kehidupan bangsa". Selain itu di perkuat dengan UU No. 20 Tahun 2003 tentang Sisdiknas (sistem pendidikan nasional) pasal 5 ayat (1) menyatakan bahwa "Setiap warga negara mempunyai hak yang sama untuk memperoleh pendidikan yang bermutu", dan pasal 11 ayat (1) menyatakan, "Pemerintah dan Pemerintah Daerah wajib memberikan layanan dan kemudahan serta menjamin terselenggaranya pendidikan yang bermutu bagi setiap warga negara tanpa diskriminasi." Keberhasilan pendidikan merupakan tanggung jawab bersama antara keluarga (orang tua), anggota masyarakat dan pemerintah. Pemerintah dan masyarakat menyediakan tempat untuk belajar yaitu sekolah. Sekolah menampung siswa-siswanya dari berbagai macam latar belakang atau kondisi sosial ekonomi yang berbeda.

Salah satu cara untuk menarik minat siswa adalah dengan meningkatkan motivasi belajar di sekolah. Motivasi belajar cara yang menjadi dorongan bagi siswa yang mampu memberikan semangat, keinginan dan gairah untuk melakukan suatu kegiatan belajar. Berbagai permasalahan antara lain yaitu siswa yang kurang berprestasi yang dialami oleh siswa KMS dikarenakan beberapa siswa KMS merasa bahwa di SMP N A para siswa tidak dapat mengoptimalkan potensinya dikarenakan bersekolah di SMP N A bukan merupakan pilihan awal dari para siswa. Ditambah lagi siswa merasa pelajaran di SMP berbeda dengan SD. Para siswa membutuhkan penjelasan yang lebih detail namun guru cenderug kurang memfasilitasi.

Siswa yang memiliki jam pelajaran kosong cenderung tidak menggunakannya dengan baik sebagaimana mestinya. Para siswa tidak memiliki cita-cita yang ingin digapai sehingga para siswa merasa dengan data bersekolah sudah dianggap cukup. Para siswa tidak memiliki tujuan yang ingin dicapai disekolah padahal menurut Locke dan Latham (2013) Penetapan tujuan menyatakan bahwa sasaran yang khusus dan sulit akan menghasilkan kinerja yang lebih tinggi.

Pada kasus SMP N A ini diketahui terlihat bahwa tidak adanya upaya dari siswa KMS untuk melakukan adaptasi, berprestasi secara akademik dan tidak melanggar aturan sekolah. Permasalahan lain menurut guru BK diakibatkan input siswa KMS ke SMP N Akurang baik. Guru BK mengatakan bahwa input siswa KMS di SMP N A nilai UN pun tidak terlalu rendah paling rendah 23 sedangkan siswa kelas reguler 26 dari 3 mata pelajaran. Biasanya siswa yang masuk ke sekolah ini dikarenakan tidak bisa masuk 
Jurnal Psikologi Terapan dan Pendidikan

ISSN: $2715-2456$

Vol. 1, No. 2, November 2019, pp. 136-142

ke sekolah negeri yang favorit, selain itu mekanisme seleksi di sekolah juga yang memiliki jalur KMS membuat lebih mudah diterima lewat jalur KMS. karena SMP N Asetiap tahun menerima sekitar 60 siswa KMS. Oleh karena itu, tidak sedikit siswa yang masuk ke SMP N AYogyakarta dalam kondisi tidak memiliki motivasi yang baik dan tujuan yang jelas. Siswa baru ini datang tanpa membawa semangat belajar karena mereka tidak menjadikan sekolah ini sebagai minat utama.

Dalam hal disiplin guru BK menganggap siswa KMS kelas VII masih banyak yang menunjukkan perilaku pelanggaran kedisiplinan seperti membolos, terlambat datang ke sekolah, tidak mengenakan atribut lengkap dan lain sebagainya. Hal itu dikarenakan kelas VII masih dalam fase adaptasi dengan lingkungan baru dari sekolah dasar menuju SMA dan banyak di antara siswa kelas VII yang mungkin masih merasa kecewa karena tidak bersekolah di sekolah yang diinginkan. Oleh karena itu siswa KMS kelas VII kemungkinan masih belum memiliki tujuan yang jelas ke depan menganai langkah yang diambil saat belajar di sekolah ini. Kelas VII KMS juga direkomendasikan oleh guru BK karena diharapkan perbaikan kondisi siswa bisa meningkatkan prestasi belajarnya sehingga lebih siap dalam mengikuti proses KBM di kelas VII dan ujian nasional di kelas VII.

Setelah melakukan analisis terhadap kelas VII, guru BK menyimpulkan bahwa kelas dengan presentase membolos pada siswa KMS kelas VII. Ketika siswa KMS VII, Siswa KMS kelas VII ini rutin setiap hari selalu ada siswa yang terlambat datang ke sekolah. Siswa KMS dianggap tidak menunjukkan keseriusan dalam belajar, dan seringkali tidak antusias selama diajar oleh guru mata pelajaran.

Santrock (2007) mengatakan bahwa motivasi adalah proses yang memberi semangat,arah, dan kegigihan perilaku. Artinya, perilaku yang memiliki motivasi adalah perilaku yang penuh energi, terarah, dan bertahan lama.Glynn dkk (2005) menyatakan bahwa motivasi merupakan kondisi internal yang memunculkan, mengarahkan, dan mempertahankan perilaku manusia. Motivasi tersebut juga memiliki peran penting dalam pembelajaran, sebagaimana yang diungkapkan oleh Brophy (Glynn dkk, 2005) bahwa motivasi belajar merupakan kecenderungan siswa untuk menemukan aktivitas akademik yang berarti dan berharga, juga untuk mencoba mendapatkan keuntungan dari aktivitas tersebut.

Santrock (2007) menjabarkan aspek motivasi belajar yaitu a) Motivasi ekstrinsik, adalah melakukan sesuatu untuk mendapatkan sesuatu yang lain (cara untuk mencapai tujuan). Motivasi ekstrinsik sering dipengaruhi oleh imbalan dan hukuman. Misalnya, murid belajar keras dalam menghadapi ujian untuk mendapatan nilai yang baik. Terdapat dua kegunaan dari hadiah, yaitu sebagai insentif agar mau mengerjakan tugas, dimana tujuannya adalah mengontrol perilaku siswa, dan mengandung informasi tentang penguasaan keahlian, b) Motivasi intrinsik, merupakan motivasi internal untuk melakukan sesuatu demi sesuatu itu sendiri (tujuan itu sendiri). Misalnya, murid belajar menghadapi ujian karena dia senang 
Jurnal Psikologi Terapan dan Pendidikan

ISSN: $2715-2456$

Vol. 1, No. 2, November 2019, pp. 136-142

pada mata pelajaran yang diujikan itu. Murid termotivasi untuk belajar saat mereka diberi pilihan, senang menghadapi tantangan yang sesuai dengan kemampuan mereka, dan mendapat imbalan yang mengandung nilai informasional tetapi bukan dipakai untuk kontrol, misalnya guru memberikan pujian kepadasiswa. Terdapat dua jenis motivasi intrinsik, antara lain motivasi intrinsik berdasarkan determinasi diri dan pilihan personal. Dalam pandangan ini, murid ingin percaya bahwa mereka melakukan sesuatu karena kemauan sendiri, bukan karena kesuksesan atau imbalan eksternal. Minat intrinsik siswa akan meningkat jika mereka mempunyai pilihan dan peluang untuk mengambil tanggung jawab personal atas pembelajaran mereka. Motivasi intrinsik berdasarkan pengalaman optimal. Pengalaman optimal kebanyakan terjadi ketika orang merasa mampu dan berkonsentrasi penuh saat melakukan suatu aktivitas serta terlibat dalam tantangan yang mereka anggap tidak terlalu sulit tetapi juga tidak terlalu mudah.

Tujuan kajian artikel ini adalah untuk mengetahui bagaimana motivasi belajar siswa dan dapat memberikan intervensi untuk siswa kms yang memiliki motivasi belajar yang rendah.

\section{METODE PENELITIAN}

Penelitian ini merupakan penelitian kuantitatif dengan subjek penelitian dalam penelitian ini adalah Siswa SMP Negeri A di Yogyakarta sebanyak 57 siswa. Pemilihan subjek berdasarkan keadaan kelas yang terdapat di sekolah, berdasarkan observasi dan wawancara siswa kms terkait perilakunya di sekolah. Pemilihan subjek melalui purposive sampling, artinya subjek dipilih berdasarkan pertimbangan kriteria tertentu, meliputi hanya siswa kelas VII. Pengambilan data penelitian ini dilaksanakan dari bulan April 2015. Penelitian dilaksanakan dengan menyusun instrumen penelitian. Pengumpulan data dalam penelitian ini dilakukan dengan menggunakan tiga skala pengukuran yaitu skala motivasi belajar yang dirancang oleh Puspita (2012) terdiri dari 39 aitem dengan reliabilitas 0,9280. Skala Motivasi Belajar digunakan untuk mengetahui seberapa tinggi motivasi belajar para siswa. Untuk mengklasifikasikan skor motivasi yang diperoleh siswa dalam kategori rendah, sedang, dan tinggi. digunakan data mean hipotetik dan standar deviasi hipotetik. Dari perhitungan mean dan standar deviasi hipotetik, diketahui kategori skor sebagai berikut a) Kategori rendah yaitu $\mathrm{x}<12$, b) Kategori sedang yaitu $127 \leq \mathrm{x}<151$, c) Kategori tinggi yaitu $\mathrm{x}$ $\geq 151$.

\section{HASIL}

Berdasarkan asesmen diketahui bahwa permasalahan siswa yang paling menonjol pada siswa KMS di SMP N A Yogyakarta adalah rendahnya perhatian siswa terhadap pelajaran dan siswa KMS yang sering terlambat datang kesekolah. Guru BK mengatakan bahwa perilaku terlambat siswa tersebut dikarenakan 
Jurnal Psikologi Terapan dan Pendidikan

ISSN: $2715-2456$

Vol. 1, No. 2, November 2019, pp. 136-142

siswa tidak punya semangat untuk bersekolah. Hal itu juga terlihat dari cukup banyak siswa yang malas penyelesaian remidi mata pelajaran yang belum mencapai KKM, selain bersikap semaunya sendiri dalam menaati peraturan sekolah. Rendahnya motivasi siswa KMS di SMP N AYogyakarta biasanya dikarenakan mereka tidak diterima di sekolah negeri yang sesuai kenginannya, sehingga menempuh pendidikan di SMP N A Yogyakarta bukan dengan keinginan sendiri.

Siswa kelas VII menunjukkan perilaku pelanggaran kedisiplinan seperti terlambat karenak siswa kelas VII masih dalam fase adaptasi dengan lingkungan baru, dan banyak di antara siswa kelas VII yang mungkin masih merasa kecewa karena tidak bersekolah di sekolah yang diinginkan. Salah satu faktor rendahnya motivasi siswa KMS kelas VII adalah siswa belum mengetahui apa kelebihan sekolah SMPN A. Mereka yang masuk SMP N A dari siswa KMS biasanya kurang setuju untuk bersekolah di SMP N A sehingga pemikiran mereka masih mengarah kepada kesenangan dan teman-teman.

Kurangnya motivasi siswa ditunjukkan dengan semangat yang kurang dan kinerjanya sangat tergantung oleh lingkungan. Belum terlihat adanya inisiatif dari siswa untuk senantiasa belajar mandiri. Siswa cenderung hanya akan bekerja jika dipaksa oleh guru atau dalam pengawasan yang ketat, jika tidak demikian siswa tidak belajar dengan baik.

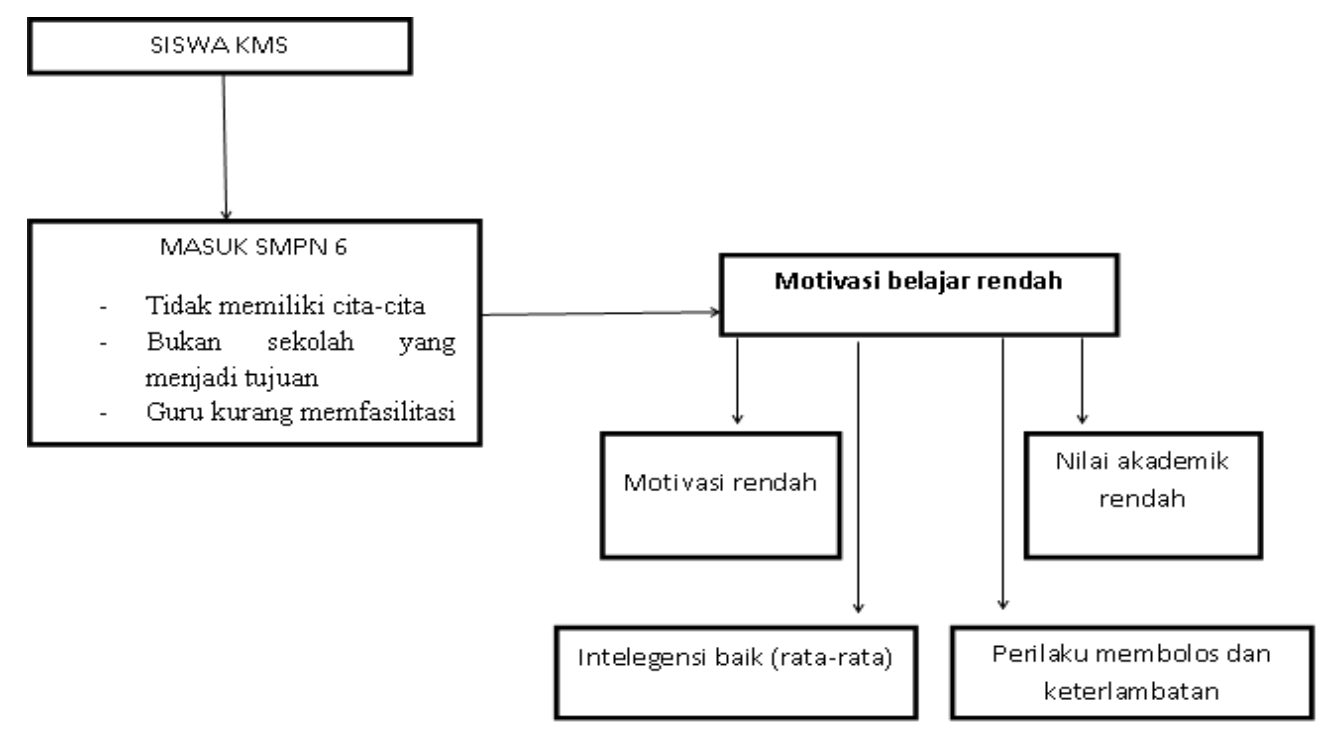

Bagan. 1 Dinamika Psikologis

\section{PEMBAHASAN}

Motivasi belajar berperan dalam tujuan akhir pembelajaran, motivasi akan membawa siswa mencapai tujuan yang diharapkan dan hasil belajar menjadi lebih maksimal. Motivasi yang baik diharapkan dapat membawa siswa mencapai prestasi belajar yang maksimal. Dari hasil penelitian dilapangan, 
menunjukkan bahwa motivasi belajar siswa KMS dalam kategori rendah sejumlah $26 \%$ atau sekitar 15 siswa, kategori sedang yaitu sebanyak 68\% atau sekitar 39 siswa, kategori rendah $6 \%$ atau sekitar siswa 3 siswa. Kondisi ini perlu ditingkatkan karena motivasi merupakan kekuatan yang terdapat dalam diri individu yang menyebabkan individu itu bertindak. Motivasi yang baik akan memudahkan guru dalam mengarahkan siswa mencapai tujuan pembelajaran. Tingkat motivasi yang sedang dan tinggi dari siswa KMS tidak terlepas dari pemberian KMS itu sendiri. Dengan adanya KMS, meskipun belum tentu siswa dapat menyesuaikan diri dengan lingkungan yang berasal dari keluarga non KMS. Kondisi ini mempengaruhi mental siswa pengguna KMS dalam belajar sehingga kurang dapat berekspresi dan bersaing dalam berprestasi dengan siswa reguler, selain itu ada faktor lain yang mempengaruhi, antara lain bukan sekolah pilihannya atau minat menjadi alasan motivasi belajar siswa KMS rendah dan juga. Siswa merasa pelajaran di SMP berbeda dengan SD, siswa membutuhkan penjelasan yang lebih detail namun guru cenderug kurang memfasilitasi. Siswa tidak memiliki jam pelajaran sendiri sehingga ketika tidak mengerti dengan pelajaran di kelas siswa cenderung tidak belajar dikarenakan tidak mengerti. Para siswa tidak memiliki cita-cita yang ingin digapai sehingga para siswa merasa dengan data bersekolah sudah dianggap cukup.
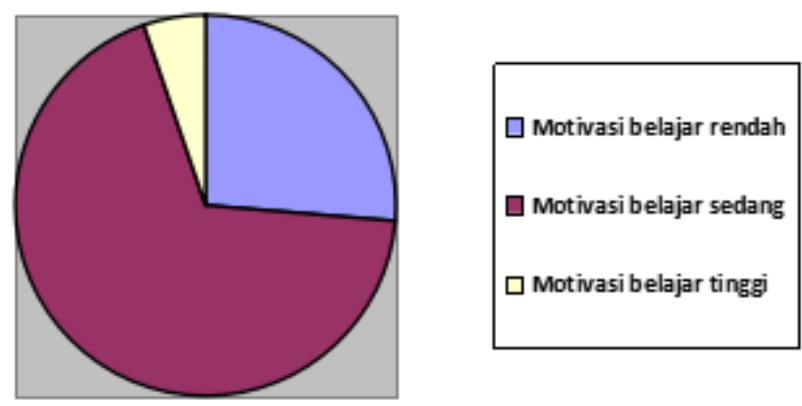

Gambar. 1 Tingkat Motivasi Belajar Siswa KMS

Tabel. 1

Tingkat Motivasi Belajar Siswa KMS

\begin{tabular}{llc}
\hline Motivasi Belajar siswa & $\begin{array}{l}\text { Jumlah } \\
\text { KMS }\end{array}$ & Prosentase \\
\hline Rendah & 15 & $26 \%$ \\
Sedang & 39 & $68 \%$ \\
Tinggi & 3 & $6 \%$ \\
\hline
\end{tabular}

\section{KESIMPULAN}

Berdasarkan analisis yang telah dipaparkan maka dirumuskan beberapa kesimpulan hasil penelitian yang dapat dimanfaatkan dalam pengembangan ilmu pengetahuan dan sebagai acuan bagi pengambil 
Jurnal Psikologi Terapan dan Pendidikan

ISSN: $2715-2456$

Vol. 1, No. 2, November 2019, pp. 136-142

kebijakan dalam dunia pendidikan. Penelitian ini menunjukkan bahwa motivasi belajar siswa KMS dalam

kategori rendah sejumlah 26\% atau sekitar 15 siswa, kategori sedang yaitu sebanyak $68 \%$ atau sekitar 39 siswa, kategori rendah $6 \%$ atau sekitar siswa 3 siswa

\section{DAFTAR PUSTAKA}

Glynn, S.M., Aultman, L.P., \& Owens, A.M. (2005). Motivation to learn in general education programs. The Journal of General Education, 54(2), 150-170.

Kirkpatrick, D. L. (1998). Evaluating training programs: The four levels. San Francisco: Berrett-Koehler Publisher, Inc.

Locke, E.A., \& Latham, G, P. (2013). New development goal setting and task performance. New York: Routledge

Santrock, J. W. (2007). Educational psychology. Boston: McGraw-Hill 